\title{
Olive oil and oxidative stress
}

\author{
By Francesco Visioli, Paola Bogani, Simona Grande and Claudio Galli
}

University of Milan, Department of Pharmacological Sciences, Milan, Italy

"Corresponding author: : Dr. Francesco Visioli. Tel: +39 0220488217

Email: francesco.visioli@unini.it

\section{CONTENTS}

1. INTRODUCTION

2. OLIVE OIL PHENOLICS AND OXIDATIVE STRESS

3. OLIVE OIL PHENOLICS AS BIOACTIVE COMPOUNDS 3.1. In vitro studies

3.1.1. Antioxidant activities

3.1.2. Beyond antioxidants. Enzyme-modulating activities

3.2. In vivo studies

4. CONCLUSIONS

ACKNOWLEDGMENTS

REFERENCES

\section{RESUMEN}

\section{Aceite de oliva y estrés oxidativo.}

La composición del aceite de oliva virgen extra se caracteriza por su contenido en ácidos grasos, fundamentalmente monoinsaturados (ácido oleico) beneficiosos para reducir el riesgo de enfermedad coronaria, y en componentes menores, particularmente polifenoles (p.e. hidroxitirosol y oleuropeína) responsables de su sabor y estabilidad. Diversos estudios demuestran el poder antioxidante de los compuestos fenólicos del aceite de oliva (virgen extra). Aunque la mayoría de ellos se han realizado in vitro, algunos in vivo parecen confirmar que los polifenoles se absorben dependiendo de la dosis y que retienen las actividades biológicas después de su ingestión. Estos resultados pueden explicar en parte la menor incidencia de enfermedad coronaria en los países del área Mediterránea, donde el aceite de oliva (extra virgen) es la principal fuente de grasas.

PALABRAS-CLAVE: Aceite de oliva; Antioxidantes; Hidroxitirosol; Dieta Mediterránea; Polifenoles; Oleuropeína.

\section{SUMMARY}

\section{Olive oil and oxidative stress.}

In addition to the fatty acid profile of olive oil, which is high in the monounsaturated oleic acid and appears to be beneficial in reducing several risk factors for coronary heart disease and certain cancers, extra virgin olive oil contains a considerable amount of phenolic compounds, e.g. hydroxytyrosol and oleuropein, that are responsible for its peculiar taste and for its high stability. A body of evidence demonstrates that olive oil phenolics are powerful antioxidants. Although most of these studies have been carried out in vitro, some in vivo experiments confirm that olive oil phenolics are dose-dependently absorbed and that they retain their biological activities after ingestion. These data could in part explain the lower incidence of coronary heart disease in the Mediterranean area, where (extra virgin) olive oil is the principal source of fat.
KEY-WORDS: Olive oil; Antioxidants; Hydroxytyrosol; Mediterranean diet; Phenolics; Oleuropein

\section{INTRODUCTION}

Atherosclerosis begins as an injury to the endothelium of the blood vessel walls (Ross, 1999; Assanelli et al., 2004; Schulz et al., 2004). Many studies reported that hyperlipidemia might injure the cell wall as well as interfere with normal responses by tissues to injury, leading to an infiltration of blood platelets, the proliferation of smooth muscle cells, and accumulation of collagen and lipids at the site of damage. Atherosclerotic plaques evolve in the narrowing of the coronary arteries that supply blood to the heart.

There is evidence that classic risk factors for coronary heart disease (CHD), such as high serum cholesterol and blood pressure, are not much different between the populations of the Mediterranean area - where the incidence of $\mathrm{CHD}$ and certain cancers, e.g. breast and colon cancers, is lowest than those of other North European and Western countries. Further, there are several observations that do not completely link CHD incidence and fat intake and absorption (Mancini and Rubba, 2000). These data suggest that other, yet unexplored risk factors may be favorably affected by a healthful diet. Conversely, in order to lower the risk of onset and progression of CHD, nutritional recommendations have been primarily focused upon dietary regimes aimed at reducing the amount of circulating lipids as well as the formation of blood clots.

These observations, together with several studies indicating a key role played by oxidation of low-density lipoproteins (LDL) in the onset of atherosclerosis (Witztum and Steinberg, 2001), led to the formulation of an antioxidant/atherosclerosis hypothesis. Polyphenolic metabolites of plants, common in the Mediterranean area, are found in fruits, vegetables and olive oil (see this issue of Grasas y Aceites), and act as strong antioxidants in various systems. Their multiple biological actions 
have been reviewed by many authors (Kris-Etherton et al., 2002). Moreover, many epidemiological studies have shown an inverse association between the consumption of fruit, vegetables, and their products and the incidence of cardiovascular diseases and cancer ( $\mathrm{Hu}$ and Willett, 2002; Kromhout et al., 2002).

Clinical and epidemiological studies have shown that the dietary factor most closely correlated with high levels of blood cholesterol and CHD risk are saturated fatty acids (SFA). The healthful properties of olive oil have been, until recently, exclusively attributed to its high monounsaturated fatty acid (MUFA) content, mostly in the form of oleic acid (18:1n-9), which ranges from 56 to $84 \%$ of total fatty acids. However, several observations argue against this hypothesis. For example, the effects of MUFA on circulating lipids and lipoproteins are still equivocal. It is generally accepted that high intakes of MUFA indirectly reduce the level of serum total cholesterol when replace SFA (Hegsted et al., 1993; Gardner and Kraemer, 1995a,b). In addition, it is also demonstrated a direct, although modest, cholesterol-lowering effect after replacement of isocaloric amounts of carbohydrates by MUFA (Mensink and Katan, 1992; Mensink et al., 2003). MUFA increase the levels of the protective high-density lipoprotein (HDL) more than polyunsaturated fatty acids (PUFA) when these two classes of fatty acids replace carbohydrates in the diet (Mensink and Katan, 1992); however, there are reports of a neutral effect of MUFA on plasma lipids or even a total- and LDL-cholesterol lowering activity. Most important, oleic acid is one of the predominant fatty acids in largely-consumed animal foods, such as poultry and pork; thus, the percentage of oleic acid in the Mediterranean diet is only slightly higher than that of other kinds of Western diets, e.g. the North American one (Dougherty et al., 1987). It is therefore unlikely that oleic acid is exclusively accountable for the healthful properties of olive oil. Finally, it is also noteworthy that several seed oils obtained through genetic selection, such as sunflower, soybean, and rapeseed oils are nowadays rich in MUFA, albeit devoid of phenolics (Owen et al., 2000), and are commercially available. Healthy effects of dietary MUFA, including lower endothelial activation (Massaro et al., 2002; Massaro and De Caterina, 2002) and susceptibility of LDL to oxidation (Berry et al., 1992; Bonanome et al., 1992), are indeed to be considered; but it is also remarkable to establish the amount and quality of phenolic compounds in extra virgin olive oils.

This issue focuses on the evidence that indicates how the phenolics of extra virgin olive oil may play a role in the protection from $\mathrm{CHD}$ and cancer observed in the Mediterranean area (see also issues 3 and 4). These effects go beyond those of oleic acid and we propose that consumption of good-quality (extra virgin) olive oil might have an important impact on our health.

\section{OLIVE OIL PHENOLICS AND OXIDATIVE STRESS}

Among the several minor compounds of virgin olive oil, there are vitamins such as $\alpha$ - and $\gamma$-tocopherols, $\beta$-carotene, phytosterols, squalene, pigments, terpenic acids, flavonoids such as luteolin and quercetin, and phenolics usually referred to as polyphenols (Boskou, 2000; Blekas et al., 2002).

As dietary antioxidants are likely capable of decreasing the incidence of CHD and certain cancers in the Mediterranean area (Trichopoulou et al., 1999), research is investigating the potentially protective activities of olive oil minor constituents, some of which (namely hydroxytyrosol and oleuropein) have been recently become commercially available.

As opposed to other vegetable oils, (extra virgin) olive oil possesses substantial amount of phenolic compounds. One of the current major limitations to natural antioxidant research is the current lack of appropriate methodologies to quantify the amount of phytochemicals, including phenolic molecules, in foods. This also applies to (extra virgin) olive oil: several methods to quantify and identify its phenolic components have been developed but they rarely agree. Currently, the most popular methods for evaluating the polyphenolic content of (extra virgin) olive oil are the Folin-Ciocalteau colorimetric assay (Visioli et al., 1995b) and the HPLC (Montedoro et al., 1992). Although the colorimetric method is simple to perform and does not require expensive equipment, it has low specificity of the reagent toward phenolic compounds and it does not provide qualitative information of the composition of the phenolic fraction. Given the importance of catecholic compounds within the phenolic fraction, this information is actually of extreme importance. Conversely, HPLC is very sensitive and specific, it can identify relevant molecules, but it is time-consuming and does not provide information on phenolic molecules for which reference standards are unavailable. Another assay, sensitive, specific, and easy to perform has been proposed by Mosca et al. (2000). This assay is based on a substrate-recycling procedure that employs tyrosinase together with $\mathrm{NADH}$ as a reducing agent. Again, this method only provides quantitative information. Finally, a rapid and sensitive method to evaluate the phenolics of olive oil by Atmospheric Pressure Chemical Ionization-Mass Spectrometry (APCl-MS) has been described by Caruso et al. (2000). This method allows for quick analyses of crude methanolic extracts of olive oil, does not need extensive analytical workup, and makes it possible to quantify oleuropein aglycone. However, the apparatus is very expensive and requires trained personnel to operate. 
In turn, the lack of reliable methodology to evaluate the quali/quantitative profile of olive oil phenolic fraction is one of the major obstacles that prevent dose-response, pharmacology-style trials in animals and humans.

\section{OLIVE OIL PHENOLICS AS BIOACTIVE COMPOUNDS}

\subsection{In vitro studies}

\subsubsection{Antioxidant activities}

In 1994, our laboratory initiated a series of experiments aimed at investigating the antioxidant activities of (extra virgin) olive oil phenolics on parameters that are considered relevant to human health. The first paper reported inhibition of LDL oxidation by oleuropein glycoside, which was, to our knowledge, the only phenol typical of olive oil that was commercially available (Extrasynthese, France).

Oleuropein was found to potently and dose-dependently inhibit LDL oxidation induced by copper sulphate (Visioli and Galli, 1994). This investigation was subsequently expanded to include hydroxytyrosol (which wasn't commercially available but was isolated from olive oil and kindly provided by Professor G.F. Montedoro, University of Perugia) and other catechols (Visioli et al., 1995a). Metal-independent oxidation was also tested and revealed that hydroxytyrosol, in addition being a metal chelator, is also a scavenger of free radicals (Visioli et al., 1995a). Subsequent experiments showed that both oleuropein and hydroxytyrosol effectively scavenge superoxide anion generated by either human polymorphonuclear cells or by the xantine/xantine oxidase system (Visioli et al., 1998a); it is noteworthy that, in these experimental setups, both vitamin $\mathrm{E}$ and butylated hydroxytoluene were found to be inactive. A scavenging effect of oleuropein and hydroxytyrosol was also demonstrated with respect to hypochlorous acid (Visioli et al., 1998a), a potent and dangerous oxidant species produced in vivo by activated neutrophils at the site of inflammation (Aruoma and Halliwell, 1987). In addition to damaging nearby molecules such as $\alpha_{1}$-antiprotease, hypochlorite is a major component of chlorine-based bleaches that can often be exposed to food during manufacturing. In terms of protection from atherosclerosis, the $\mathrm{HOCl}$-scavenging property of hydroxytyrosol may bear important consequences: evidence is rapidly accumulating that the formation of chloramines via the myeloperoxidase-catalyzed formation of $\mathrm{HOCl}$ and subsequent chlorination of apo $\mathrm{B}-100$ is responsible for LDL modification and peroxidation (Carr et al., 2000).

It is of interest that similar antioxidant activities were discovered in the major by-product of olive oil production (e.g. olive mill waste-water), which is very rich in phenolic molecules [actually, due to their partition coefficient, olive phenols are more abundant in waste-water than in olive oil (Rodis et al., 2002)] and might be employed in preservative chemistry (Visioli et al., 1995b; Visioli et al., 1999; Leger et al., 2000; Visioli and Galli, 2003). Indeed, the lack of appropriate disposal techniques for waste-waters (Demicheli and Bontoux, 1996) and the increasing need for antioxidants of natural origin make olive mill waste-waters an appealing resource of bioactive molecules, which can be selectively recovered (Italian patent $\left.n^{\circ} B O 2001 A 00419\right)$ from this abundant source.

Following our initial observations, other laboratories joined in this line of research to further investigate the antioxidant properties of olive phenols. For example, hydroxytyrosol proved to be effective in a model of oxidative stress induced in intestinal epithelial cells (Manna et al., 1997). Conversely, tyrosol, which lacks the ortho-diphenolic structure, was found to be ineffective in this experimental model, as it was in the models of LDL oxidation described above (unpublished data). Manna et al. (1999) also described a protective effect of hydroxytyrosol toward hydrogen peroxide-induced damage to human erythrocyte. Vascular production of superoxide anion is associated with increased risk for endothelial dysfunction and cardiovascular disease (Schulz et al., 2004). As indicated above, oleuropein and hydroxytyrosol were found to be very effective scavengers of superoxide (Table 1).

Damage to DNA is associated with increased risk for cancer. The activities of hydroxytyrosol toward chemically-induced DNA and aminoacid modification have been investigated (Deiana et al., 1999) and it was found that low concentrations of hydroxytyrosol, e.g. $50 \mu \mathrm{M}$, are able to scavenge peroxynitrite and therefore to prevent $\mathrm{ONOO}^{\circ}$-dependent DNA damage and tyrosine nitration. Scavenging of peroxynitrite was further confirmed (de la Puerta et al., 2001).

A matter of concern in oxidant/antioxidant chemistry is the prooxidant potential of several molecules, including antioxidants with strong reducing capabilities. The prooxidant activities of hydroxytyrosol were investigated in a model of copper-induced DNA damage and were found to be were 40-fold weaker than those of ascorbate. Further, these actions occurred only at very high, non-physiological concentrations $(>500 \mu \mathrm{M})$ (Deiana et al., 1999).

The mechanism of action of olive oil phenolics are related to their $o$-diphenolic structure, which increase radical stability by forming an intra-molecular hydrogen bond between the free hydrogens of their hydroxyl group and their phenoxyl radicals (Visioli et al., 1998a). Although studies on structure-activity of 
Table 1

Inibition of superoxide anion formation rates by olive oil phenolics

\begin{tabular}{lll}
\hline & \multicolumn{2}{l}{ Superoxide-producing system } \\
\hline & Xantine-xantine oxidase & PMN + PMA \\
\hline Hydroxytyrosol (IC50) & $9.1 \mu \mathrm{M}$ & $3.2 \mu \mathrm{M}$ \\
\hline Oleuropein (IC50) & $14.3 \mu \mathrm{M}$ & $29.3 \mu \mathrm{M}$ \\
\hline
\end{tabular}

The mean inhibiting concentration (IC50) was calculated by employing MacALLFIT as software. PMN, human polymorphonuclear neutrophils; PMA, phorbol-12-myristate-13 acetate. From Visioli et al. (1998a).

olive oil phenolics are yet to be carried out, similar investigations performed on phenolic molecules indicated that the degree of antioxidant activity is correlated with the number of hydroxyl substitutions (Rice-Evans et al., 1996). In particular, the $\mathrm{o}-\mathrm{diOH}$ (catecholic) substitution confers a high antioxidant capacity, whereas single hydroxyl substitutions, as in the case of tyrosol, lack antioxidant activity.

\subsubsection{Beyond antioxidants. Enzyme-modulating activities}

One of the most interesting aspects of olive oil phenolics' biochemistry is the discovery of their enzyme-modulating properties, which, in some cases, are unrelated to their antioxidant potential. In fact, most olive oil phenolics are amphiphilic and they partition between the lipid (olive oil) and water (waste-water) phases. Therefore, they might be able to interact with enzymes relevant to human pathology, namely atherosclerosis.

For example, hydroxytyrosol was proven to inhibit chemically-induced in vitro platelet aggregation, the accumulation of the pro-aggregant agent thromboxane $\left(\mathrm{TxA}_{2}\right)$ in human serum, the production of the pro-inflammatory molecules leukotrienes by activated human leukocytes, and the arachidonate lipoxygenase (Petroni et al., 1995; Kohyama et al., 1997; de la Puerta et al., 1999; de la Puerta et al., 2000; Martinez-Dominguez et al., 2001). The mean inhibiting concentrations $\left(\mathrm{IC}_{50}\right)$ were found to be in the $10^{-5} \mathrm{M}$ range, indicating unpredicted biological activities of olive oil phenolics that go beyond their antioxidant properties.

Concerning the immuno-modulating properties of olive oil phenolics, in vitro studies on murine macrophages revealed that oleuropein increases the functional response of these immune-competent cells when they are stimulated with bacterial polysaccharide, as evaluated by a significant increase $(+58.7 \pm 4.6 \%$, mean $\pm S D)$ in the production of nitric oxide (Visioli et al., 1998b). It is noteworthy that this increase is due to a direct tonic effect of oleuropein, which increases both the activity and the expression of the inducible form of the enzyme nitric oxide synthase (iNOS). As relevant to atherosclerosis, it should be noted that during acute sepsis and inflammation that take place in the arterial wall, macrophages react to the endotoxin challenge by increasing the production of nitric oxide, which inhibits platelet aggregation and adherence and maintains a proper end-organ perfusion rate through increased vaso-relaxation. In agreement with this finding, inhibition of nitric oxide synthesis during sepsis increases cellular damage and animal mortality (Lowenstein et al., 1996). Finally, macrophagic nitric oxide exerts antioxidant activities that play a protective role in preventing oxidative LDL modification that occur at the site of

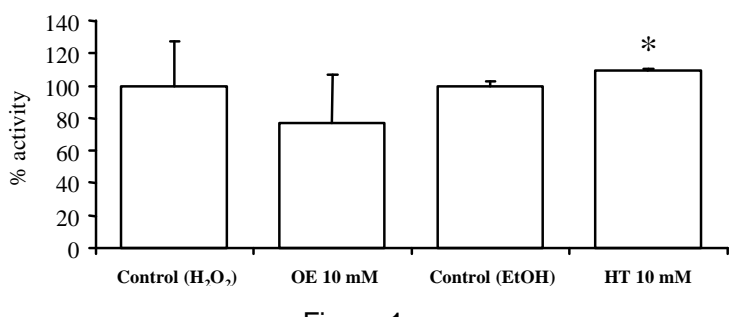

Figure 1

Hydroxytyrosol (HT) and oleuropein glycoside (OE) do not inhibit MMP-2 activity in bovine aortic endothelial cells (BAEC). BAEC were incubated for 24 hours at $37^{\circ} \mathrm{C}$ with DMEM supplemented with $0.2 \%$ BSA in the absence (control) or in the presence of HT or OE $10 \mu \mathrm{M}$. Gelatinolytic activity was detected by SDS-PAGE zymography on $7.5 \%$ polyacrylamide gels containing $10 \%$ SDS and gelatin $(1 \mathrm{mg} / \mathrm{mL})$ under non-reductive conditions. After electrophoresis, SDS was removed from the gel by two washes with $2.5 \%$ Triton $\mathrm{X}-100$. At the end of the incubation, gels were stained with a solution of $\mathrm{NaCl}(150 \mathrm{mmol} / \mathrm{L}), \mathrm{CaCl}_{2}(10 \mathrm{mmol} / \mathrm{L})$, and $\mathrm{ZnCl}_{2}(1 \mathrm{~mol} / \mathrm{L})$. Areas of lysis appeared after renaturing and staining of gels with Coomassie brilliant-blue

7R-250. Gelatinolytic bands were quantified by densitometry (software: NIH Image 1.52). Statistical significance was investigated by Student's $t$ test with two--tailed distribution (software:

SPSS 11.0 version). * $p<0.01$ compared to controls. Unpublished data. 
inflammation during enhanced reactive oxygen species production (Jessup et al., 1999).

More recently, we studied the activities of olive phenols on other enzymes relevant to cardiovascular disease, e.g. metalloproteases (MMP). These are enzymes can degrade the atherosclerotic plaque, leading to plaque instability and enhancing possibility to release thrombi. As shown in Figure 1, olive phenols are unable to down-regulate MMP's activity in bovine aortic endothelial cells, which was actually mildly enhanced by hydroxytyrosol supplementation. Further experiments will clarify whether this lack of effect applies to other MMP and if it is unique to oleuropein and hydroxytyrosol.

\subsection{In vivo studies}

Notwithstanding the hype that is currently surrounding natural antioxidants and their healthful effects, very limited number of controlled trials proves their efficacy in vivo. Experimental evidence that flavonoids and phenolic compounds are absorbed from the diet is accumulating (Bravo, 1998) and this includes olive oil phenolics. Studies with laboratory animals have demonstrated a higher resistance to oxidation of LDL obtained from animals fed virgin olive oil, as compared to LDL separated from animals that were only administered an equivalent amount of oleic acid as either triolein (Scaccini et al., 1992) or "plain" olive oil (Wiseman et al., 1996). Visioli et al. (2000b) demonstrated the dose-dependent absorption of olive oil phenolics in humans and that their urinary excretion as glucuronide conjugates; another interesting finding of that study was that increasing amounts of phenolics administered with olive oil stimulated the rate of conjugation with glucuronide. These findings were confirmed by other laboratories (Miro-Casas et al., 2001; Vissers et al., 2002; Miro-Casas et al., 2003a; Miro-Casas et al., 2003b), and recent data shed light on the human metabolism of hydroxytyrosol (Caruso et al., 2001). From studies carried out in human intestinal Caco-2 cells, it appears that hydroxytyrosol is absorbed from the gut by passive diffusion (Manna et al., 2000) and that it is extensively metabolized before being excreted with the urine. Whether circulating metabolites still exert biological actions is still under investigation, although data from other laboratories that study tea components, namely quercetin, suggest even higher antioxidant potential of the metabolites as compared with the parent molecule (Moon et al., 2001).

Interestingly, the bioavailability of hydroxytyrosol is higher when this molecule is administered as natural component of olive oil than when it is given after addition to olive oil or to yogurt, as approximation of a functional food (Visioli et al., 2003a). These data actually add to the notion that oligonutrients bioavailability is lower than such compounds isolated from their original matrix and administered as supplements (Visioli et al., 2003b).

In vivo evidence of the antioxidant activity of (extra virgin) olive oil phenolics, namely hydroxytyrosol, is also accumulating. In addition to the effects on LDL oxidation reported above, we have been recently able to demonstrate that hydroxytyrosol, administered to animals as the only bioactive component of an olive mill waste-water extract, is dose-dependently absorbed and is able to increase their plasma antioxidant capacity (Visioli et al., 2001). Further, low doses of hydroxytyrosol, e.g. $414 \mu \mathrm{g} /$ animal, are able to inhibit passive smokinginduced oxidative stress in animals, as demonstrated by a reduced urinary excretion of the $\mathrm{F}_{2}$-isoprostane 8-iso-PGF ${ }_{2 \alpha}\left(\mathrm{iPF}_{2 \alpha}\right.$-III) (Visioli et al., 2000c). Finally, a dose-dependent inhibition of the rate of 8-iso-PGF ${ }_{2 \alpha}$ excretion was observed in human volunteers who ingested olive oils added with increasing amounts of phenolics (Visioli et al., 2000a). Interestingly, the urinary levels of 8-iso-PGF $\mathrm{PG}_{2 \alpha}$ inversely correlated with those of homovanillyl alcohol, e.g. a catechol-o-methyl -transferase (COMT)-derived metabolite of hydroxytyrosol (Manna et al., 1999; Lamensdorf et al., 2000), suggesting that this phenol

Table 2

Concentrations of olive oil test agents causing initial cytotoxicity towards human cells in culture. These concentrations are far above those reachable in vivo, even though they might me attained locally (e.g. in the mouth)

\begin{tabular}{lccc}
\hline & \multicolumn{3}{c}{ Concentration (mM) } \\
\hline Test agent & GN61 & S-G & HSG $_{1}$ \\
\hline oleuropein aglycone & 0.66 & 0.66 & 0.33 \\
oleuropein glycoside & 1.0 & 1.0 & 1.5 \\
caffeic acid & 1.5 & 3.0 & 2.0 \\
o-coumaric acid & 6.0 & 3.0 & 3.0 \\
cinnamic acid & 6.75 & 4.0 & 5.0 \\
tyrosol & $>10.0$ & 3.0 & 5.0 \\
syringic acid & 9.0 & 6.0 & 5.0 \\
protocatechuic acid & 10.0 & 5.0 & 7.5 \\
vanillic acid & 10.0 & 10.0 & 10.0 \\
\hline
\end{tabular}


Table 3

Antioxidant and additional biological actions of olive oil phenolics

Action

Antioxidant activities, in vitro

Inhibition of LDL oxidation

Inhibition of apolipoprotein modification

Scavenging of free radicals and other oxidants

Inhibition of platelet aggregation

Reduced cyclo- and lipoxygenase activation

Increased nitric oxide production by LPS-challenged macrophages

Inhibition of neutrophil respiratory burst

Cellular activities

Inhibition of bacterial growth and activity

Decreased endothelial activation

Cytostasis

Ex vivo and in vivo activities

Increased plasma antioxidant capacity and (Ramirez-Tortosa et al, 1999; Visioli et al., 2001; resistance of LDL to oxidation

Antiinflammatory activity

Decreased isoprostane excretion in humans and in sidestream smoke-exposed animals

Decreased $\mathrm{T} \times \mathrm{B}_{2}$ production by human serum

Vasomodulation
Reference(s)

(Scaccini et al., 1992; Grignaffini et al., 1994; Visioli and Galli, 1994; Salami et al., 1995; Visioli et al., 1995a; Visioli et al., 1995b; Wiseman et al., 1996; Aruoma et al., 1998; Leenen et al., 2002; Wiseman et al., 2002; Benkhalti et al., 2003)

(Visioli et al., 1995a)

(Le Toutour and Guedon, 1992; Aeschbach et al., 1994; Manna et al., 1997; Saija et al., 1998; Speroni et al., 1998; Visioli et al., 1998a; Manna et al., 1999; Fogliano et al., 1999; Leger et al., 2000; Benavente-Garcia et al., 2000; de la Puerta et al., 2001; Casalino et al., 2002; Briante et al., 2002; Quiles et al., 2002)

(Aruoma et al., 1998; Deiana et al., 1999)

(Petroni et al., 1995)

(Petroni et al., 1995; Kohyama et al., 1997; Petroni et al., 1997; Visioli et al., 1999; de la Puerta R. et al., 1999; Brzosko et al., 2002)

(Visioli et al., 1998b)

(Visioli et al., 1998a)

(Tranter et al., 1993; Capasso et al., 1995; Bisignano et al., 1999)

(Carluccio et al., 2003)

(Saenz et al., 1998) Masella et al., 2001; Ochoa et al., 2002; Fito et al., 2002; Wiseman et al., 2002) (de la Puerta et al., 2000; Martinez-Dominguez et al., 2001)

(Visioli et al., 2000a; Visioli et al., 2000c)

(Visioli and Galli, 2003)

(Panizzi et al., 1960; Benkhalti et al., 2003) 
enters into cellular compartments where it exerts its antioxidant activity. As other laboratories failed to detect any biological effect of extra virgin olive oil administration (Vissers et al., 2001a,b), no clear conclusion can be drawn and further experiments are needed before any health claim can be made.

As far as toxicity of (extra virgin) olive oil phenolics is concerned, very few data are available that did not show toxic effects of hydroxytyrosol in animals (D'Angelo et al., 2001) and cell cultures (Table 2) (Babich and Visioli, 2003).

Currently, there is a serious lack of methodology to allow for controlled human trails. In addition to the uncertainty that surrounds the determination of phytochemicals in foods, their detection in human fluids/tissues is even more problematic. Moreover, there is no reliable method to detect the effect of antioxidant supplementation on human oxidative status; until a reliable biomarker is validated (Halliwell, 2000; Halliwell et al., 2004), it is impossible to carry out controlled studies on the antioxidant activities of oligonutrients, including those of olive oil (Visioli, 2004).

\section{CONCLUSIONS}

It is now clear that the incidence of degenerative pathologies, including those in which the excessive free radical formation has been suggested, is very low in the Mediterranean area, where the diet is rich in antioxidant compounds (Keys, 1995; Willett et al., 1995; Trichopoulou et al., 2003). Among such antioxidants, the contribution of olive oil phenolics is under active investigation (Table 3). Even though researchers are far from being able to make claims, based on the current data it is advisable to suggest the use of extra virgin olive oil as the predominant source of fat of a healthful, Mediterranean diet. The intake of bioactive molecules (hydroxytyrosol, oleuropein) through olive oil might contribute to lower the risk of developing CHD and certain cancers.

\section{ACKNOWLEDGMENTS}

Work in our laboratory is currently supported by EEC grant QLK-2001-00173. Some of the work described in this review has been supported by EEC grant FAIR CT 973039 and by Carapelli spa.

\section{REFERENCES}

Aeschbach, R., Loliger, J., Scott, B.C., Murcia, A., Butler, J., Halliwell, B., Aruoma, O.I. (1994). Antioxidant actions of thymol, carvacrol, 6-gingerol, zingerone and hydroxytyrosol. Food Chem. Toxicol., 32, 31-36.

Aruoma, O.I., Deiana, M., Jenner, A., Halliwell, B., Harpakash, K., Banni, S., Corongiu, F.P., Dessi, M.A., Aeschbach, R. (1998). Effect of hydroxytyrosol found in extra virgin olive oil on oxidative DNA damage and on low-density lipoprotein oxidation. J. Agric. Food Chem., 46, 5181-5187.

Aruoma, O.I., Halliwell, B. (1987). Action of hypochlorous acid on the antioxidant protective enzymes superoxide dismutase, catalase and glutathione peroxidase. Biochem. J., 248, 973-976.

Assanelli, D., Bonanome, A., Pezzini, A., Albertini, F., Maccalli, P., Grassi, M., Archetti, S., Negrini, R., Visioli, F. (2004). Folic acid and vitamin E supplementation effects on homocysteinemia, endothelial function and plasma antioxidant capacity in young myocardialinfarction patients. Pharmacol. Res., 49, 79-84.

Babich, H., Visioli, F. (2003). In vitro cytotoxicity to human cells in culture of some phenolics from olive oil. Farmaco, 58, 403-407.

Benavente-Garcia, O., Castillo, J., Lorente, J., Ortuño, A., Del Rio, J.A. (2000). Antioxidant activity of phenolics extracted from Olea europaea L. leaves. Food Chem., 68, 457-462.

Benkhalti, F., Legssyer, A., Gomez, P., Paz, E., Lopez-Miranda, J., Perez-Jimenez, F., el Boustani, E.S. (2003). Effects of virgin olive oil phenolic compounds on LDL oxidation and vasorelaxation activity. Therapie, 58, 133-137.

Berry, E.M., Eisenberg, S., Friedlander, Y., Harats, D., Kaufmann, N.A., Norman, Y., Stein, Y. (1992). Effects of diets rich in monounsaturated fatty acids on plasma lipoproteins--the Jerusalem Nutrition Study. II. Monounsaturated fatty acids vs carbohydrates. Am. J. Clin. Nutr., 56, 394-403.

Bisignano, G., Tomaino, R., Lo Cascio, R., Crisalfi, G., Uccella, N., Saija, A. (1999). On the in-vitro antimicrobial activity of oleuropein and hydroxytyrosol. J. Pharm. Pharmacol., 51, 971-974.

Blekas, G., Vassilakis, C., Harizanis, C., Tsimidou, M., Boskou, D.G. (2002). Biophenols in table olives. J. Agric. Food Chem., 50, 3688-3692.

Bonanome, A., Pagnan, A., Biffanti, S., Opportuno, A., Sorgato, F., Dorella, M., Maiorino, M., Ursini, F. (1992). Effect of dietary monounsaturated and polyunsaturated fatty acids on the susceptibility of plasma low density lipoproteins to oxidative modification. Arterioscler. Thromb., 12, 529-533.

Boskou, D. (2000). Olive oil. World Rev. Nutr. Diet, 87, 56-77.

Bravo, L. (1998). Polyphenols: chemistry, dietary sources, metabolism, and nutritional significance. Nutr. Rev., 56, 317-333.

Briante, R., Patumi, M., Terenziani, S., Bismuto, E., Febbraio, F., Nucci, R. (2002). Olea europaea L. leaf extract and derivatives: antioxidant properties. J. Agric. Food Chem., 50, 4934-4940.

Brzosko, S., De Curtis, A., Murzilli, S., de Gaetano, G., Donati, M.B., lacoviello, L. (2002). Effect of extra virgin olive oil on experimental thrombosis and primary hemostasis in rats. Nutr. Metab. Cardiovasc. Dis., 12, 337-342.

Capasso, R., Evidente, A., Schivo, L., Orru, G., Marcialis, M.A., Cristinzio, G. (1995). Antibacterial polyphenols from olive oil mill waste waters. J. Appl. Bacteriol., 79, 393-398.

Carluccio, M.A., Siculella, L., Ancora, M.A., Massaro, M., Scoditti, E., Storelli, C., Visioli, F., Distante, A., De Caterina, R. (2003). Olive oil and red wine antioxidant polyphenols inhibit endothelial activation: antiatherogenic properties of mediterranean diet phytochemicals. Arterioscler. Thromb. Vasc. Biol., 23, 622-629. 
Carr, A., McCall, M.R., Frei, B. (2000). Oxidation of LDL by myeloperoxidase and reactive nitrogen species. Arterioscler. Thromb. Vasc. Biol., 20, 1716-1723.

Caruso, D., Colombo, R., Patelli, R., Giavarini, F., Galli, G. (2000). Rapid evaluation of phenolic component profile and analysis of oleuropein aglycon in olive oil by atmospheric pressure chemical ionization-mass spectrometry (APCI-MS). J. Agric. Food Chem., 48, $1182-1185$

Caruso, D., Visioli, F., Patelli, R., Galli, C., Galli, G. (2001). Urinary excretion of olive oil phenols and their metabolites in humans. Metabolism, 50, 1426-1428.

Casalino, E., Calzaretti, G., Sblano, C., Landriscina, V., Felice, T. M., Landriscina, C. (2002). Antioxidant effect of hydroxytyrosol (DPE) and $\mathrm{Mn2+}$ in liver of cadmium-intoxicated rats. Comp. Biochem. Physiol. C Toxicol. Pharmacol., 133, 625-632.

D’Angelo, S., Manna, C., Migliardi, V., Mazzoni, O., Morrica, P., Capasso, G., Pontoni, G., Galletti, P., Zappia, V. (2001). Pharmacokinetics and metabolism of hydroxytyrosol, a natural antioxidant from olive oil. Drug Metab. Dispos., 29, 1492-1498.

de la Puerta, R., Ruiz-Gutierrez, V., Hoult, J.R. (1999). Inhibition of leukocyte 5-lipoxygenase by phenolics from virgin olive oil. Biochem. Pharmacol., 57, 445-449.

de la Puerta, R., Martinez, D.M., Ruiz-Gutierrez, V., Flavill, J.A., Hoult, J.R. (2001). Effects of virgin olive oil phenolics on scavenging of reactive nitrogen species and upon nitrergic neurotransmission. Life Sci., 69, 1213-1222.

de la Puerta, R., Martinez-Dominguez, E., Ruiz-Gutierrez, $V$. (2000). Effect of minor components of virgin olive oil on topical antiinflammatory assays. Z. Naturforsch., 55, 814-819.

Deiana, M., Aruoma, O.I., Bianchi, M.L., Spencer, J.P., Kaur, H., Halliwell, B., Aeschbach, R., Banni, S., Dessi, M.A., Corongiu, F.P. (1999). Inhibition of peroxynitrite dependent DNA base modification and tyrosine nitration by the extra virgin olive oil-derived antioxidant hydroxytyrosol. Free Radic. Biol. Med., 26, 762-769.

Demicheli, M., Bontoux, L. Survey on current activity on the valorization of by-products from the olive oil industry. 1996. IPTS. Ref Type: Pamphlet.

Dougherty, R.M., Galli, C., Ferro-Luzzi, A., lacono, J.M. (1987). Lipid and phospholipid fatty acid composition of plasma, red blood cells, and platelets and how they are affected by dietary lipids: a study of normal subjects from Italy, Finland, and the USA. Am. J. Clin. Nutr., 45, 443-455.

Fito, M., Gimeno, E., Covas, M.I., Miro, E., Lopez-Sabater, M.C., Farre, M., de, T.R., Marrugat, J. (2002). Postprandial and short-term effects of dietary virgin olive oil on oxidant/antioxidant status. Lipids, 37, 245-251.

Fogliano, V., Ritieni, A., Monti, S.M., Gallo, M., Della Medaglia, D., Ambrosino, M.L., Sacchi, R. (1999). Antioxidant activity of virgin olive oil phenolic compounds in a micellar system. J. Sci. Food Agric., 79, $1803-1808$.

Gardner, C.D., Kraemer, H.C. (1995a). Monounsaturated versus polyunsaturated dietary fat and serum lipids. A meta-analysis. Arterioscler. Thromb. Vasc. Biol., 15, 1917-1927.

Gardner, C.D., Kraemer, H.C. (1995b). Monounsaturated versus polyunsaturated dietary fat and serum lipids. A meta-analysis. Arterioscler. Thromb. Vasc. Biol., 15, 1917-1927.

Grignaffini, P., Roma, P., Galli, C., Catapano, A.L. (1994). Protection of low-density lipoprotein from oxidation by 3,4-dihydroxyphenylethanol. Lancet, 343, 1296-1297.
Halliwell, B., Long, L.H., Yee, T.P., Lim, S., Kelly, R. (2004). Establishing biomarkers of oxidative stress. The measurement of hydrogen peroxide in human urine. Curr. Med. Chem., 11, 1085-1092.

Halliwell, B. (2000). Lipid peroxidation, antioxidants and cardiovascular disease: how should we move forward? Cardiovasc. Res., 47, 410-418.

Hegsted, D.M., Ausman, L.M., Johnson, J.A., Dallal, G.E. (1993). Dietary fat and serum lipids: an evaluation of the experimental data. Am. J. Clin. Nutr., 57, 875-883.

Hu, F.B., Willett, W.C. (2002). Optimal diets for prevention of coronary heart disease. JAMA, 288, 2569-2578.

Jessup, W., Mohr, D., Gieseg, S.P., Dean, R.T., Stocker, R. (1999). The participation of nitric oxide in cell free- and its restriction of macrophage-mediated oxidation of low-density lipoprotein. Biochim. Biophys. Acta, 1180, 73-82.

Keys, A. (1995). Mediterranean diet and public health: personal reflections. Am. J. Clin. Nutr., 61, 1321S-1323S.

Kohyama, N., Nagata, T., Fujimoto, S., Sekiya, K. (1997). Inhibition of arachidonate lipoxygenase activities by 2-(3,4-dihydroxyphenyl)ethanol, a phenolic compound from olives. Biosci. Biotechnol. Biochem., 61, 347-350.

Kris-Etherton, P.M., Hecker, K.D., Bonanome, A., Coval, S.M., Binkoski, A.E., Hilpert, K.F., Griel, A.E., Etherton, T.D. (2002). Bioactive compounds in foods: their role in the prevention of cardiovascular disease and cancer. Am. J. Med., 113, 71-88.

Kromhout, D., Menotti, A., Kesteloot, H., Sans, S. (2002) Prevention of coronary heart disease by diet and lifestyle: evidence from prospective cross-cultural, cohort, and intervention studies. Circulation, 105, 893-898.

Lamensdorf, I., Eisenhofer, G., Harvey-White, J., Hayakawa, Y., Kirk, K., Kopin, I.J. (2000). Metabolic stress in PC12 cells induces the formation of the endogenous dopaminergic neurotoxin, 3,4-dihydroxyphenylacetaldehyde. J. Neurosci. Res., 60, 552-558.

Le Toutour, B., Guedon, D. (1992). Antioxidant activities of Olea Europaea leaves and related phenolic compounds. Phytochemistry, 31, 1173-1178.

Leenen, R., Roodenburg, A.J., Vissers, M.N., Schuurbiers, J.A., van Putte, K.P., Wiseman, S.A., van De Put, F.H. (2002). Supplementation of plasma with olive oil phenols and extracts:[?] Influence on LDL oxidation. J. Agric. Food Chem., 50, 1290-1297.

Leger, C.L., Kadiri-Hassani, N., Descomps, B. (2000). Decreased superoxide anion production in cultured human promonocyte cells (THP-1) due to polyphenol mixtures from olive oil processing wastewaters. J. Agric. Food Chem., 48, 5061-5067.

Lowenstein, C.J., Hill, S.L., Lafond-Walker, A, Wu, J. Allen, G., Landavere, M., Rose, N.R., Herskowitz, A. (1996). Nitric oxide inhibits viral replication in murine myocarditis. J. Clin. Invest., 97, 1837-1843.

Mancini, M., Rubba, P. (2000) The Mediterranean diet in Italy. In Mediterranean diets (Simopoulos, A.P. and Visioli, F., eds) pp. 114-126, Karger, Basel.

Manna, C., Galletti, P., Cucciolla, V., Moltedo, O., Leone, A., Zappia, V. (1997). The protective effect of the olive oil polyphenol (3,4-dihydroxyphenyl)-ethanol counteracts reactive oxygen metabolite-induced cytotoxicity in Caco-2 cells. J. Nutr., 127, 286-292.

Manna, C., Galletti, P., Cucciolla, V., Montedoro, G. F., Zappia, V. (1999). Olive oil hydroxytyrosol protects human erythrocytes against oxidative damage. J. Nutr. Biochem., 10, 159-165. 
Manna, C., Galletti, P., Maisto, G., Cucciolla, V., D’Angelo, S., Zappia, V. (2000). Transport mechanism and metabolism of olive oil hydroxytyrosol in Caco-2 cells. FEBS Lett., 470, 341-344.

Martinez-Dominguez, E., de la Puerta, R., Ruiz-Gutierrez, V. (2001). Protective effects upon experimental inflammation models of a polyphenol-supplemented virgin olive oil diet. Inflamm. Res., 50, 102-106.

Masella, R., Giovannini, C., Vari, R., Di Benedetto, R., Coni, E., Volpe, R., Fraone, N., Bucci, A. (2001). Effects of dietary virgin olive oil phenols on low density lipoprotein oxidation in hyperlipidemic patients. Lipids, 36, 1195-1202.

Massaro, M., Basta, G., Lazzerini, G., Carluccio, M.A., Bosetti, F., Solaini, G., Visioli, F., Paolicchi, A., De Caterina, R. (2002). Quenching of intracellular ROS generation as a mechanism for oleate-induced reduction of endothelial activation and early atherogenesis. Thromb. Haemost., 88, 335-344.

Massaro, M., De Caterina, R. (2002). Vasculoprotective effects of oleic acid: epidemiological background and direct vascular antiatherogenic properties. Nutr. Metab. Cardiovasc. Dis., 12, 42-51.

Mensink, R.P., Katan, M.B. (1992). Effect of dietary fatty acids on serum lipids and lipoproteins. Arterioscler. Thromb. Vasc. Biol., 12, 911-919.

Mensink, R.P., Zock, P.L., Kester, A.D., Katan, M.B. (2003). Effects of dietary fatty acids and carbohydrates on the ratio of serum total to HDL cholesterol and on serum lipids and apolipoproteins: a meta-analysis of 60 controlled trials. Am. J. Clin. Nutr., 77, 1146-1155.

Miro-Casas, E., Covas, M.I., Farre, M., Fito, M., Ortuno, J., Weinbrenner, T., Roset, P., De la Torre, R. (2003a). Hydroxytyrosol disposition in humans. Clin. Chem., 49, 945-952.

Miro-Casas, E., Covas, M.I., Fito, M., Farre-Albadalejo, M., Marrugat, J., De la Torre, R. (2003b). Tyrosol and hydroxytyrosol are absorbed from moderate and sustained doses of virgin olive oil in humans. Eur. $J$. Clin. Nutr., 57, 186-190.

Miro-Casas, E., Farre, A.M., Covas, M.I., Rodriguez, J.O., Menoyo, C.E., Lamuela, R.R., de la Torre, R. (2001). Capillary gas chromatography-mass spectrometry quantitative determination of hydroxytyrosol and tyrosol in human urine after olive oil intake. Anal. Biochem., 294, 63-72.

Montedoro, G.F., Servili, M., Baldioli, M., Miniati, E. (1992). Simple and hydrolyzable phenolic compounds in virgin olive oil. 1. Their extraction, separation, and quantitative and semiquantitative evaluation by HPLC. J. Agric. Food Chem., 40, 1571-1576.

Moon, J.H., Tsushida, T., Nakahara, K., Terao, J. (2001). Identification of quercetin 3-O-beta-D-glucuronide as an antioxidative metabolite in rat plasma after oral administration of quercetin. Free Radic. Biol. Med., 30, 1274-1285

Mosca, L., De Marco, C., Visioli, F., Cannella, C. (2000). Enzymatic assay for the determination of olive oil polyphenol content: assay conditions and validation of the method. J. Agric. Food Chem., 48, 297-301.

Ochoa, J.J., Quiles, J.L., Ramirez-Tortosa, M.C., Mataix, J., Huertas, J.R. (2002). Dietary oils high in oleic acid but with different unsaponifiable fraction contents have different effects in fatty acid composition and peroxidation in rabbit LDL. Nutrition, 18, 60-65.

Owen, R.W., Mier, W., Giacosa, A., Hull, W.E., Spiegelhalder, B., Bartsch, H. (2000). Identification of lignans as major components in the phenolic fraction of olive oil. Clin. Chem., 46, 976-988.
Panizzi, L.M., Scarpati, J.M., Oriente, E.G. (1960). Costituzione dell'oleuropeina, glucoside amaro ed ad azione ipotensiva dell'olivo. Gazzetta Chimica Italiana, 90, 1449-1485.

Petroni, A., Blasevich, M., Papini, N., Salami, M., Sala, A., Galli, C. (1997). Inhibition of leukocyte leukotriene B4 production by an olive oil-derived phenol identified by mass-spectrometry. Thromb. Res., 87, 315-322.

Petroni, A., Blasevich, M., Salami, M., Papini, N., Montedoro, G.F., Galli, C. (1995). Inhibition of platelet aggregation and eicosanoid production by phenolic components of olive oil. Thromb. Res., 78, 151-160.

Quiles, J.L., Farquharson, A.J., Simpson, D.K., Grant, I., Wahle, K.W. (2002). Olive oil phenolics: effects on DNA oxidation and redox enzyme mRNA in prostate cells. Br. J. Nutr., 88, 225-234.

Ramirez-Tortosa, M.C., Urbano, G., Lopez-Jurado, M., Nestares, T., Gomez, M.C., Mir, A., Ros, E., Mataix, J., Gil, A. (1999). Extra-virgin olive oil increases the resistance of LDL to oxidation more than refined olive oil in free-living men with peripheral vascular disease. J. Nutr., 129, $2177-2183$.

Rice-Evans, C.A., Miller, N.J., Paganga, G. (1996). Structure-antioxidant activity relationships of flavonoids and phenolic acids. Free Radic. Biol. Med., 20, 933-956.

Rodis, P.S., Karathanos, V.T., Mantzavinou, A. (2002). Partitioning of olive oil antioxidants between oil and water phases. J. Agric. Food Chem., 50, 596-601.

Ross, R. (1999). Atherosclerosis--an inflammatory disease. N. Engl. J. Med., 340, 115-126.

Saenz, M.T., Garcia, M.D., Ahumada, M.C., Ruiz, V. (1998). Cytostatic activity of some compounds from the unsaponifiable fraction obtained from virgin olive oil. Farmaco, 53, 448-449.

Saija, A., Trombetta, D., Tomaino, A., Lo Cascio, R., Princi, P., Uccella, N., Bonina, F., Castelli, F. (1998). In vitro evaluation of the antioxidant activity and biomembrane interaction of the plant phenols oleuropein and hydroxytyrosol. Int. J. Pharmac., 166, 123-133.

Salami, M., Galli, C., De Angelis, L., Visioli, F. (1995). Formation of F2-isoprostanes in oxidized low density lipoprotein: inhibitory effect of hydroxytyrosol. Pharmacol. Res., 31, 275-279.

Scaccini, C., Nardini, M., D’Aquino, M., Gentili, V., Di Felice, M., Tomassi, G. (1992). Effect of dietary oils on lipid peroxidation and on antioxidant parameters of rat plasma and lipoprotein fractions. J. Lipid Res., 33, 627-633.

Schulz, E., Anter, E., Keaney, J.F. (2004). Oxidative stress, antioxidants, and endothelial function. Curr. Med. Chem., 11, 1093-1104.

Speroni, E., Guerra, M.C., Minghetti, A., Crespi-Perellino, N., Pasini, P., Piazza, F., Roda, A. (1998). Oleuropein evaluated in vitro and in vivo as an antioxidant. Phytother. Res., 12, S98-S100.

Tranter, H.S., Tassou, S.C., Nychas, G.J. (1993). The effect of the olive phenolic compound, oleuropein, on growth and enterotoxin $B$ production by Staphylococcus aureus. J. Appl. Bacteriol., 74, 253-259.

Trichopoulou, A., Costacou, T., Bamia, C., Trichopoulos, D. (2003). Adherence to a Mediterranean diet and survival in a Greek population. N. Engl. J. Med., 348, 2599-2608.

Trichopoulou, A., Vasilopoulou, E., Lagiou, A. (1999). Mediterranean diet and coronary heart disease: are antioxidants critical?. Nutr. Rev., 57, 253-255.

Visioli, F. (2004). The roller coaster of antioxidant therapy. Curr. Med. Chem., 11, 3 p. preceeding 1085. 
Visioli, F., Bellomo, G., Galli, C. (1998a). Free radical-scavenging properties of olive oil polyphenols. Biochem. Biophys. Res. Commun., 247, 60-64.

Visioli, F., Bellomo, G., Montedoro, G., Galli, C. (1995a) Low density lipoprotein oxidation is inhibited in vitro by olive oil constituents. Atherosclerosis, 117, 25-32.

Visioli, F., Bellosta, S., Galli, C. (1998b). Oleuropein, the bitter principle of olives, enhances nitric oxide production by mouse macrophages. Life Sci., 62 , 541-546.

Visioli, F., Caruso, D., Galli, C., Viappiani, S., Galli, G., Sala, A. (2000a). Olive oils rich in natural catecholic phenols decrease isoprostane excretion in humans. Biochem. Biophys. Res. Commun., 278, 797-799.

Visioli, F., Caruso, D., Plasmati, E., Patelli, R., Mulinacci, N., Romani, A., Galli, G., Galli, C. (2001). Hydroxytyrosol, as a component of olive mill waste water, is dose-dependently absorbed and increases the antioxidant capacity of rat plasma. Free Radic. Res., 34, 301-305.

Visioli, F., Galli, C. (1994). Oleuropein protects low density lipoprotein from oxidation. Life Sci., 55, 1965-1971.

Visioli, F., Galli, C. (2003). Olives and their production waste products as sources of bioactive compounds. Curr. Topics Nutr. Research, 1, 85-88.

Visioli, F., Galli, C., Bornet, F., Mattei, A., Patelli, R., Galli, G., Caruso, D. (2000b). Olive oil phenolics are dose-dependently absorbed in humans. FEBS Lett., 468, 159-160.

Visioli, F., Galli, C., Grande, S., Colonnelli, K., Patelli, C., Galli, G., Caruso, D. (2003a). Hydroxytyrosol excretion differs between rats and humans and depends on the vehicle of administration. J. Nutr., 133, 2612-2615.

Visioli, F., Galli, C., Plasmati, E., Viappiani, S., Hernandez, A., Colombo, C., Sala, A. (2000c). Olive phenol hydroxytyrosol prevents passive smoking-induced oxidative stress. Circulation, 102, 2169-2171.
Visioli, F., Rise, P., Barassi, M., Marangoni, F., Galli, C. (2003b). Dietary intake of fish, vs. formulations, leads to higher plasma concentrations of $\mathrm{n}-3$ fatty acids. Lipids, 38, 415-418.

Visioli, F., Romani, A., Mulinacci, N., Zarini, S., Conte, D., Vincieri, F.F., Galli, C. (1999). Antioxidant and other biological activities of olive mill waste waters. J. Agric. Food Chem., 47, 3397-3401.

Visioli, F., Vinceri, F.F., Galli, C. (1995b). 'Waste waters' from olive oil production are rich in natural antioxidants. Experientia, 51, 32-34.

Vissers, M.N., Zock, P.L., Leenen, R., Roodenburg, A.J., van Putte, K.P., Katan, M.B. (2001a). Effect of consumption of phenols from olives and extra virgin olive oil on LDL oxidizability in healthy humans. Free Radic. Res., 35, 619-629.

Vissers, M.N., Zock, P.L., Roodenburg, A.J., Leenen, R., Katan, M.B. (2002). Olive oil phenols are absorbed in humans. J. Nutr., 132, 409-417.

Vissers, M.N., Zock, P.L., Wiseman, S.A., Meyboom, S., Katan, M.B. (2001b). Effect of phenol-rich extra virgin olive oil on markers of oxidation in healthy volunteers. Eur. J. Clin. Nutr., 55, 334-341.

Willett, W.C., Sacks, F., Trichopoulou, A., Drescher, G., Ferro-Luzzi, A., Helsing, E., Trichopoulos, D. (1995). Mediterranean diet pyramid: a cultural model for healthy eating. Am. J. Clin. Nutr., 61, 1402S-1406S.

Wiseman, S.A., Mathot, J.N., de Fouw, N.J., Tijburg, L.B. (1996). Dietary non-tocopherol antioxidants present in extra virgin olive oil increase the resistance of low density lipoproteins to oxidation in rabbits. Atherosclerosis, 120, 15-23.

Wiseman, S.A., Tijburg, L.B., van De Put, F.H. (2002). Olive oil phenolics protect LDL and spare vitamin $\mathrm{E}$ in the hamster. Lipids, 37, 1053-1057.

Witztum, J.L., Steinberg, D. (2001). The oxidative modification hypothesis of atherosclerosis: does it hold for humans?. Trends Cardiovasc. Med., 11, 93-102. 